\title{
Cerebellar neurochemical and histopathological changes in rat model of Parkinson's disease induced by intrastriatal injection of rotenone
}

\author{
Yasser A. Khadrawy ${ }^{1}$, Iman M. Mourad ${ }^{2}$, Haitham S. Mohammed ${ }^{3}$, Neveen A. Noor ${ }^{2}$ \\ and Heba S. Aboul Ezz ${ }^{2}$ \\ ${ }^{1}$ Medical Physiology Department, Medical Division, National Research Center, Giza, Egypt \\ ${ }^{2}$ Zoology Department, Faculty of Science, Cairo University, Giza, Egypt \\ ${ }^{3}$ Biophysics Department, Faculty of Science, Cairo University, Giza, Egypt
}

\begin{abstract}
The aim of the present work was to investigate the neurochemical changes induced in the cerebellum of rat model of Parkinson's disease (PD). Rats were divided into two groups; control and rat model of PD induced by the intrastriatal injection of rotenone. As compared to control, a significant increase in the excitatory amino acid neurotransmitters; glutamate and aspartate together with a significant decrease in the inhibitory amino acids, GABA, glycine and taurine were observed in the cerebellum of rat model of PD. This was associated with a significant increase in lipid peroxidation, nitric oxide and tumor necrosis factor- $\alpha$ and a significant decrease in reduced glutathione. A significant decrease in acetylcholinesterase and a significant increase in $\mathrm{Na}^{+}, \mathrm{K}^{+}$-ATPase were recorded in the cerebellum of rat model of PD. In addition the cerebellar sections from rat model of PD showed marked necrosis of Purkinje cells, irregular damaged cells, cytoplasmic shrinkage, necrosis and perineuronal vacuolation. The present results indicate that the disturbance in the balance between the excitatory and inhibitory amino acids may have a role in the pathogenesis of PD. According to the present neurochemical and histopathological changes, the cerebellum should be taken into consideration during the treatment of PD.
\end{abstract}

Key words: Cerebellum — Parkinson's disease — Amino acid neurotransmitters — Oxidative stress - Rats

Abbreviations: AChE, acetylcholinesterase; CNS, central nervous system; DTNB, 5,5'-dithiobis-(2-nitrobenzoic acid); GABA, 4-gamma aminobutyric acid; GSH, reduced glutathione; MDA, malondialdehyde; NMDA, N-methyl-D-aspartate; NO, nitric oxide; PD, Parkinson's disease; TNF- $\alpha$, tumor necrosis factor-alpha.

\section{Introduction}

Parkinson's disease (PD) is an age-related progressive neurodegenerative disorder. PD is characterized by dopaminergic neurons degeneration in the substantia nigra and subsequent depletion of the striatal dopamine content leading to bradykinesia, resting tremor, rigidity, and loss of postural balance (Moore et al. 2005). Glutamate excitotoxicity, oxida-

Correspondence to: Yasser A Khadrawy, Department of Medical Physiology, Medical Division, National Research Center, ElBehouth St., Giza, Egypt

E-mail: yaserask@yahoo.com tive stress, and mitochondrial impairment are the primary factors leading to neuronal death (Schulz et al. 2000; Sayre et al. 2001). Moore et al. (2005) reported that mitochondrial dysfunction and oxidative stress have been considered to play an important role in the pathophysiological mechanisms underlying PD.

Although the decreased dopamine level in the basal ganglia represents the major target for clinical and experimental research (Hornykiewicz 2006), much evidence suggests the involvement of cerebellar dysfunction together with the basal ganglia in mediating many Parkinsonian symptoms (Wu and Hallett 2013). The two subcortical areas, cerebellum and basal ganglia, have been reported to affect multiple 
motor, cognitive and afferent behaviors (Strick et al. 2009). The anatomical two way connection between the cerebellum and basal ganglia emphasizes the role of the cerebellum in PD (Bostan et al. 2010). In addition, a disynaptic connection has been elucidated between the cerebellum and striatum in rats (Hoshi et al. 2005).

At the onset of tremor episodes, it has been found that the basal ganglia are transiently activated, whereas tremors amplitude-related activity is correlated with the cerebellothalamo-cortical circuit (Helmich et al. 2011). These findings indicate that resting tremors may result from a pathological interaction between the basal ganglia and the cerebellothalamo-cortical circuit while tremor generation may be triggered by activity in the basal ganglia (Lewis et al. 2011).

Pathologically, in rat and monkey model of PD induced by 6 -hydroxydopamine, it has been found that degeneration of nigrostriatal dopaminergic neurons causes dysfunction of the basal ganglia-thalamic and cerebello-thalamic pathways (Rolland et al 2007). In addition, the mouse model of PD induced by MPTP (1-methyl-4-phenyl-1,2,3,6-tetrahydropyridine) showed loss of Nissil-stained Purkinje cells (Takada et al. 1993). Morphometrically, a significant reduction in the left cerebellum was observed in patients at an early stage of PD compared with control subjects (Borghammer et al. 2010). Using brain imaging in PD patients and a variety of motor tasks, hyperactivation was detected in the primary motor cortex (Sabatini et al. 2000; Haslinger et al. 2001) and cerebellum (Wu and Haltett 2005). This hyperactivation has been viewed as a strategy of the central nervous system (CNS) to compensate for defective function in the basal ganglia (Sabatini et al. 2000; Wu and Haltett 2005).

Jiao et al. (2008) have shown the involvement of N-methyl-D-aspartate (NMDA) receptor subunits - NMDAR1, NMDA2B in the cerebellum in motor learning of the mouse. In addition, in cerebellar local circuits, GABAergic neurons play a role in lateral inhibition and negative feedback mechanisms on the Purkinje and granule cells. Elimination of GABAergic input from the Golgi cells in the cerebellar granular layer caused over excitation of granule cells resulting in severe ataxia during the acute phase (Watanabe et al. 1998). Excitotoxicity induced by massive release of glutamate may be counteracted by the simultaneous enhanced release of inhibitory 4-gamma aminobutyric acid (GABA) and taurine (Saransaari and Oja 1997, 1998).

The aim of the present study is to investigate the pathophysiological role of the cerebellum in the rat model of PD induced by intrastriatal rotenone injection. This was carried out by measuring the concentration of cerebellar amino acid neurotransmitters, the activities of $\mathrm{AChE}$ and $\mathrm{Na}^{+}, \mathrm{K}^{+}$ATPase, the levels of TNF- $\alpha$ and some oxidative stress parameters in the cerebellum of lesioned animals. The present study extended to examine the histopathological changes induced in the cerebellum of the present Parkinsonian rat model.

\section{Materials and Methods}

\section{Animals}

Twenty male Wistar rats, obtained from the Animal House of the National Research Centre, Cairo, weighing between 230 and $250 \mathrm{~g}$ were used. They were housed under temperatureand light-controlled conditions with standard laboratory rodent chow and water provided ad libitum. Animal procedures were carried out according to the Ethics Committee of the National Research Centre which follows the recommendations of the National Institutes of Health Guide for Care and Use of Laboratory Animals (publication no. 85-23, revised 1985).

\section{Chemicals}

Rotenone was purchased from Sigma Chemical Co. (St. Louis, MO, USA). It was dissolved in dimethyl sulfoxide (DMSO) which was also purchased from Sigma Chemical Co. (St. Louis, MO, USA). Absolute ethyl alcohol, triethylamine, sulfanilamide, N-1-naphthylethylene diamine, thiobarbituric acid, perchloric acid, and trichloroacetic acid were obtained from Sigma Aldrich. In addition, acetylthiocholine iodide, 5,5'-dithiobis-(2-nitrobenzoic acid) (DTNB), glutathione, ethylene diaminetetracetic acid, and phosphate buffers were purchased from Sigma Aldrich. Analytical-grade lithium carbonate, dansyl chloride, glacial acetic acid, and high-performance liquid chromatography (HPLC)-grade acetonitrile were obtained from Fisher (UK). Free amino acids for standard and HPLC-grade methanol were purchased from BDH (England).

\section{Surgical procedures and experimental design}

Experimental animals were divided into 2 groups - control $(n=10)$ and PD-induced $(n=10)$. Rats were anaesthetized with sodium pentobarbital ( $40 \mathrm{mg} / \mathrm{kg}$, i.p.). After shaving the hair from the fronto-occipital area, antisepsis was performed with $2 \%$ iodine solution. A hole of $0.5 \mathrm{~mm}$ was made to the right of the bregma until the dura matter was exposed. With the use of a Hamilton syringe fitted with a 30-gauge needle, the solution of rotenone $(10 \mu \mathrm{g} / 3 \mu \mathrm{l} / \mathrm{rat})$ was injected, $1 \mu \mathrm{l} /$ min, into the right striatum at AP $0.0, \mathrm{~L}-2.5, \mathrm{~V} 5.5 \mathrm{~mm}$ relative to bregma as described by Mulcahy et al. (2011). Using the previous coordinates, control rats were injected with DMSO ( $3 \mu \mathrm{l} / \mathrm{rat})$. After the injection, burr hole was sealed with bone wax and antibiotic powder (neosporin) was sprayed at the incision. After surgery, the animals were left for four weeks to establish the animal model of PD as described by Mulcahy et al. (2011).

Four weeks after surgery, all animals were sacrificed. The brain of each rat was rapidly removed and the cerebellum was dissected out and divided into two equal halves. Each half 
was weighed and stored at $-53^{\circ} \mathrm{C}$ until analyzed. The right halves were used for assaying amino acid neurotransmitters. The left halves were homogenized in 5\% w/v $20 \mathrm{mMTris}-\mathrm{HCl}$ buffer, $\mathrm{pH} 7.4$, centrifuged and used for the analysis of acetylcholinesterase $(\mathrm{AChE})$ and $\mathrm{Na}^{+}, \mathrm{K}^{+}$-ATPase activities and the levels of malondialdehyde (MDA), reduced glutathione (GSH), nitric oxide (NO) and tumor necrosis factor-alpha (TNF- $\alpha$ ). Two cerebella of each group were used for histopathological examination.

\section{Determination of amino acid concentrations}

The quantitative determination of the amino acids (glutamate, aspartate, glutamine, GABA, glycine, and taurine) was carried out by using the high performance liquid chromatography (HPLC) method employed by Márquez et al. (1986).

\section{Tissue preparation}

Each cerebellar half was homogenized in $2 \mathrm{ml} \mathrm{75 \%} \mathrm{ethyl}$ alcohol and $2 \mathrm{ml}$ were used to rinse the homogenizer (Heidolph, Germany). Then the homogenates were centrifuged at $15,777 \times g$ at $4^{\circ} \mathrm{C}$ in a high speed cooling centrifuge (Type $3 \mathrm{k}-30$, Sigma, Germany) for $30 \mathrm{~min}$. The clear supernatant was evaporated to dryness and frozen.

\section{Dansylation reaction}

Dansyl derivatization was carried out according to the method of Tapuhi et al. (1981). Dried samples were dissolved in $0.5 \mathrm{ml}$ lithium carbonate solution ( $40 \mathrm{mM}$ adjusted to $\mathrm{pH} 9.5$ with conc. $\mathrm{HCl})$ containing 2 -aminobutyric acid $(0.08 \mathrm{mg}$ / $\mathrm{ml}$ ) as an internal standard and then treated with $0.5 \mathrm{ml}$ of dansyl chloride in acetonitrile $(3 \mathrm{mg} / \mathrm{ml})$. A standard amino acid mixture (containing glutamic acid, glutamine, aspartic acid, GABA, glycine, and taurine) was prepared by dissolving a known weight of each amino acid in lithium carbonate solution containing 2-aminobutyric acid to obtain a concentration of $0.01 \mu \mathrm{mol}$ for each amino acid. This mixture was then dansylated as the sample. After stirring, both the sample and standard mixture were placed in an incubator at $38^{\circ} \mathrm{C}$ for $1 \mathrm{~h}$. The samples were then removed from the incubator, transferred to an Eppendorf tube and centrifuged at $2817 \times g$ for $15 \mathrm{~min}$ to remove the particulate matter. The supernatant was filtered through a Hamilton syringe provided with a $13 \mathrm{~mm}$ diameter (pore size $0.4 \mu \mathrm{m}$ ) disposable syringe filter. $10 \mu \mathrm{l}$ of each sample and standard were finally injected into the HPLC system.

\section{Determination of lipid peroxidation}

MDA, as a measure of lipid peroxidation, was assayed in the cerebellum according to the method of Ruiz-Larrea et al. (1994). Thiobarbituric acid reactive substances react with thiobarbituric acid to produce a red colored complex whose peak absorbance was read at $532 \mathrm{~nm}$ in a Helios Alpha UV-Visible spectrophotometer (ThermoSpectronic, England).

\section{Determination of reduced glutathione}

Ellman's method (1959) was used to measure GSH. The procedure is based on the reduction of Ellman's reagent by - $\mathrm{SH}$ groups of GSH to form 2-nitro-s-mercaptobenzoic acid whose intense yellow color is measured spectrophotometrically at $412 \mathrm{~nm}$.

\section{Determination of nitric oxide level}

NO levels were measured using Griess reagent according to the method of Moshage et al. (1995). Since nitrite is a stable end product of the nitric oxide radical, it is used as an indicator for NO. It is converted to a deep purple azo compound after the addition of Griess reagent. This purple/magenta color is read spectrophotometrically at $540 \mathrm{~nm}$.

\section{Determination of acetylcholinesterase activity}

The procedure used for the determination of AChE activity was based on the method of Ellman et al. (1961) as modified by Gorun et al. (1978). The principle of the method depends on the hydrolysis of acetylthiocholine iodide by acetycholinesterase to produce thiocholine which reacts with the $-\mathrm{SH}$ reagent DTNB. DTNB is reduced to thionitrobenzoic acid, a yellow colored anion whose absorption is read spectrophotometrically at $412 \mathrm{~nm}$.

\section{Determination of $\mathrm{Na}^{+}, \mathrm{K}^{+}$-ATPase activity}

$\mathrm{Na}^{+}, \mathrm{K}^{+}$-ATPase activity was measured spectrophotometrically according to Bowler and Tirri (1974) as described by Tsakiris et al. (2000a). $\mathrm{Na}^{+}, \mathrm{K}^{+}$-ATPase activity was calculated as the difference between total ATPase activity $\left(\mathrm{Na}^{+}, \mathrm{K}^{+}\right.$, $\mathrm{Mg}^{2+}$-dependent) and $\mathrm{Mg}^{2+}$-dependent ATPase activity. The color developed is read at $640 \mathrm{~nm}$.

\section{Determination of TNF- $\alpha$}

Estimation of TNF- $a$ level in the cerebellum was carried out using rat TNF- $\alpha$ ELISA Kit supplied by Koma Biotech INC, Seoul (Korea). An anti-rat TNF- $a$ coating antibody is adsorbed onto microwells. Rat TNF-a present in the sample or standard binds to antibodies adsorbed to the microwells. A biotin conjugated anti-rat TNF- $\alpha$ antibody is added and binds to the rat TNF- $\alpha$ which was captured by the first antibody. Following incubation, streptavidin-horseradish peroxidase (streptavidin- 
HRP) is added and binds to the biotin conjugated anti-rat TNF- $\alpha$ antibody. After incubation, the substrate solution reactive with HRP is added to the wells. A colored product is formed equivalent to the amount of rat TNF- $\alpha$ present in the sample or standard. The reaction is terminated by the addition of acid and the absorbance is measured at $450 \mathrm{~nm}$. A standard curve is prepared from seven rat TNF- $\alpha$ standard dilutions and rat TNF- $\alpha$ concentration in the sample is determined.

\section{Statistical analyses}

The data were expressed as means \pm standard error of mean (S.E.M.). All variables were tested for normal distribution and compared using the independent Student's $t$-test. All analyses were performed using the Statistical Package for Social Sciences (SPSS) software in a compatible computer and the significance was set at $p<0.05$. The percentage difference $(\% \mathrm{D})$ was calculated as follows:

$\% \mathrm{D}=[($ Treated Value - Control Value $) /$ Control Value $]$ $\times 100$.

\section{Histology}

Histological studies were carried out primarily for confirmative/illustrative purposes. For assessment by means of light microscopy, the brains were fixed in $10 \%$ formaldehyde, embedded in paraffin, and cut serially at $8 \AA$ A sections. Routine staining of sections with hematoxylin-eosin (H\&E) was performed.

\section{Results}

\section{Neurochemical results}

As shown in Table 1, there is a significant difference in the levels of the cerebellar amino acid neurotransmitters between control and rat model of PD. Student's $t$-test showed a significant increase in the cerebellar excitatory amino acids glutamate $(40.48 \%)$ and aspartate $(20.92 \%)$ and the amide, glutamine $(14.58 \%)$ in the rat model of PD as compared to control. In addition, the cerebellar inhibitory amino acids GABA, glycine and taurine decreased significantly in PDinduced rats recording $-43.47 \%,-48.25 \%$ and $-9.97 \%$ below the control values, respectively.

Table 2 showed significant increases in cerebellar NO, lipid peroxidation and TNF- $\alpha$ in the rat model of PD recording $44.54 \%, 53.52 \%$ and $49.15 \%$ above the control values, respectively. This was accompanied by a significant decrease in reduced glutathione level $(-28.27 \%)$. In addition, the present findings revealed a significant decrease in AChE activity (-56.49\%) and a significant increase in $\mathrm{Na}^{+}$, $\mathrm{K}^{+}$-ATPase activity $(40.70 \%)$ in the cerebellum of rat model of PD (Table 2).

\section{Histopathological results}

Histopathological examination of the cerebellum from control group revealed a normal neuronal structure. Neurons retained their shape and normal cellular configuration with obvious

Table 1. Changes in amino acid neurotransmitters in the cerebellum of rat model of Parkinson's disease (PD)

\begin{tabular}{lrrrrr}
\hline Neurotransmitters $(\mu \mathrm{mol} / \mathrm{g})$ & \multicolumn{1}{c}{ Control } & $n$ & $\mathrm{PD}$ & $n$ & $\% \mathrm{D}$ \\
\hline Glutamine & $6.902 \pm 0.176$ & 6 & $7.908 \pm 0.340^{*}$ & 7 & 14.58 \\
Glutamate & $10.608 \pm 0.309$ & 7 & $14.902 \pm 0.352^{*}$ & 7 & 40.48 \\
Aspartate & $6.721 \pm 0.097$ & 7 & $8.127 \pm 0.383^{*}$ & 7 & 20.92 \\
GABA & $4.879 \pm 0.249$ & 7 & $2.758 \pm 0.122^{*}$ & 7 & -43.47 \\
Glycine & $8.406 \pm 0.305$ & 7 & $4.350 \pm 0.166^{*}$ & 7 & -48.25 \\
Taurine & $16.371 \pm 0.453$ & 7 & $14.739 \pm 0.514^{*}$ & 7 & -9.97 \\
\hline
\end{tabular}

Values represent the mean \pm S.E.M. ${ }^{*} p<0.05$ vs. Control. $\% \mathrm{D}$, percentage difference: $\% \mathrm{D}=[($ Group value - Control value $) /$ Control value $] \times 100$.

Table 2. Changes in the levels of nitric oxide (NO), lipid peroxidation (MDA), reduced glutathione (GSH) and tumour necrosis factoralpha (TNF- $\boldsymbol{\alpha}$ ) and the activities of acetylcholinesterase (AChE) and $\mathrm{Na}^{+}, \mathrm{K}^{+}$-ATPase in the cerebellum of rat model of PD

\begin{tabular}{lccrrr}
\hline & Control & $n$ & PD & $n$ & $\% \mathrm{D}$ \\
\hline $\mathrm{NO}(\mathrm{mmol} / \mathrm{g})$ & $0.119 \pm 0.006$ & 7 & $0.172 \pm 0.006^{*}$ & 6 & 44.54 \\
$\mathrm{MDA}(\mathrm{nmol} / \mathrm{g})$ & $24.166 \pm 3.287$ & 6 & $37.099 \pm 3.533^{*}$ & 6 & 53.52 \\
$\mathrm{GSH}(\mathrm{mmol} / \mathrm{g})$ & $1.574 \pm 0.167$ & 7 & $1.129 \pm 0.039^{*}$ & 8 & -28.27 \\
$\mathrm{TNF}-\alpha(\mu \mathrm{g} / \mathrm{g})$ & $1.878 \pm 0.121$ & 6 & $2.801 \pm 0.109^{*}$ & 6 & 49.15 \\
$\mathrm{AChE}(\mathrm{mmol} \mathrm{SH} / \mathrm{g} / \mathrm{min})$ & $2.135 \pm 0.169$ & 7 & $0.929 \pm 0.077^{*}$ & 7 & -56.49 \\
$\mathrm{Na}^{+}, \mathrm{K}^{+}$-ATPase $(\mathrm{mmol} \mathrm{Pi} / \mathrm{g} / \mathrm{m})$ & $1.565 \pm 0.111$ & 7 & $2.202 \pm 0.115^{*}$ & 7 & 40.70 \\
\hline
\end{tabular}

Values represent the mean \pm S.E.M. ${ }^{\star} p<0.05 v$ s. Control. $\% \mathrm{D}$, percentage difference: $\% \mathrm{D}=[($ Group value - Control value $) /$ Control value $] \times 100$. 
nuclei (Figure 1A). The cerebellar sections from rat model of PD showed marked necrosis of Purkinje cells which had indistinct boundaries. The sections also exhibited irregular damaged cells and cytoplasmic shrinkage. There was evidence of pyknotic nuclei and chromatin condensation. Necrosis and perineuronal vacuolation were also observed (Figure 1B).

\section{Discussion}

The present rat model of PD was induced by unilateral intrastriatal rotenone injection which produces many of the neuropathological and behavioral features of human PD (Mulcahy et al. 2011). In addition, a recent study from our laboratory (Khadrawy et al. 2016) has shown that the unilateral intrastriatal injection of rotenone resulted in a significant decrease in dopamine content in the midbrain and striatum and changes in motor behavior. The authors concluded that these alterations support the success of this rat model of $\mathrm{PD}$ induced by rotenone.

The present study revealed the presence of neurochemical and histopathological changes in the cerebellum of rat model of PD induced by the intrastriatal injection of rotenone. This may change the strategy of the disease treatment that depends mainly on the restoration of dopamine levels in the basal ganglia.

The present findings showed the development of hyperexcitability in the cerebellum of PD-induced rats. This was indicated from the significant increase in the excitatory amino acid neurotransmitters, glutamate and aspartate and the significant decrease in the inhibitory amino acids, GABA, glycine and taurine. These neurotransmitters are involved in many functions such as motor behavior, cognition, and emotion (Schmidt et al. 1992). The balance between excitatory and inhibitory neurotransmission is important for brain to sustain proper neuronal function (Mel and Schiller 2004).
A

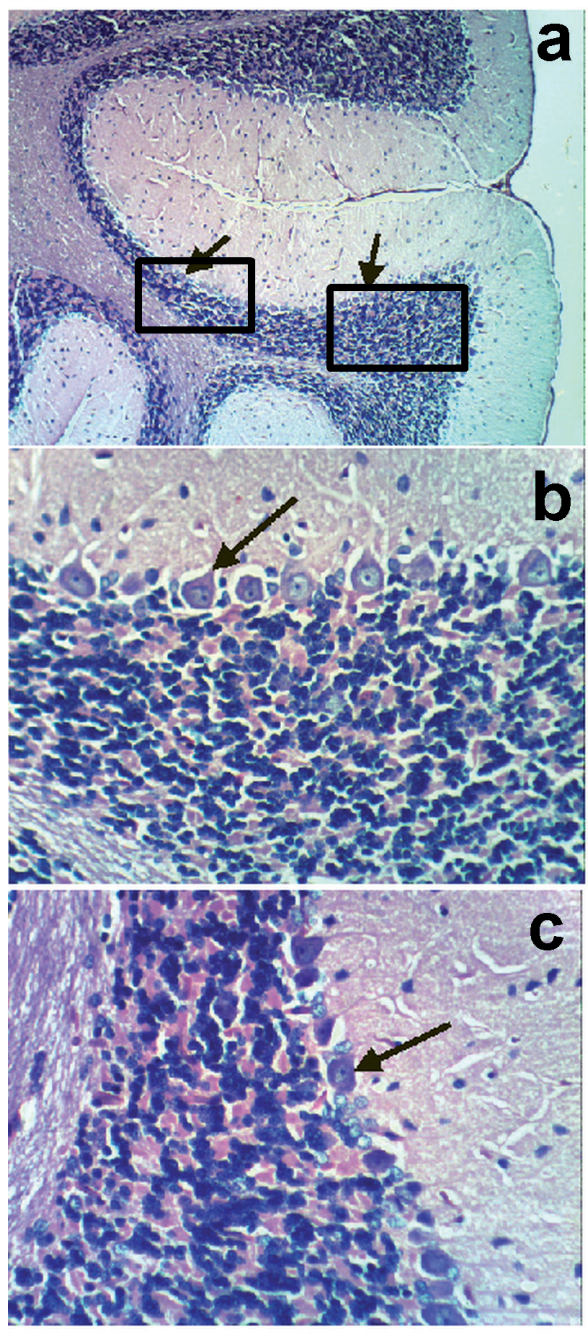

B

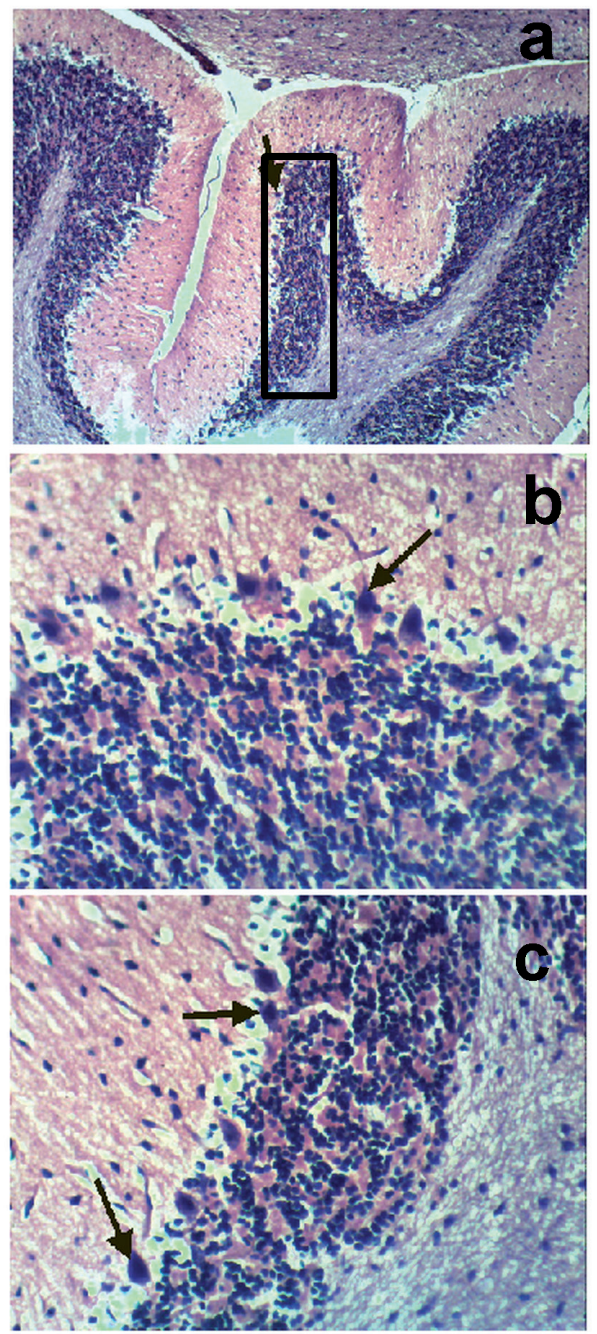

Figure 1. A. Section of the cerebellum of control rats showing no histopathological changes with normal Purkinje cells. The black arrows point to normal Purkinje neurons. The rectangles in a indicate the parts of the cerebellum that are magnified in $\mathbf{b}$ and $\mathbf{c}$ ( $\mathbf{a}$ : $\mathrm{H} \& \mathrm{E} \times 100$, b and c: $\mathrm{H} \& \mathrm{E} \times 400$ ). B. Cerebellar section of rat model of PD induced by intrastriatal injection of rotenone showing necrosis of Purkinje cells with indistinct boundaries. There was evidence of pyknotic nuclei and chromatin condensation. The black arrows point to the shrunken Purkinje neurons. The rectangle in a indicates the part of the cerebellum that is magnified in $\mathbf{b}$ and c. (a: $\mathrm{H} \& \mathrm{E} \times 100$, b and c: $\mathrm{H} \& \mathrm{E} \times 400)$. 
Sanacora et al. (2004) reported that perturbation in glutamatergic and GABAergic neurotransmission is associated with several neurological and psychiatric disorders.

Functional neuroimaging study using positron emission tomography (PET) or blood oxygen level-dependent functional magnetic resonance imaging (MRI) frequently demonstrated increased activation in the cerebellum in patients with PD during performance of various upper limb movements (Wu and Hallett 2005; Wu et al. 2010). Increased activation of the cerebellum in PD appears not only during motor execution but also during the motor learning process (Bedard and Sanes 2009). The hyperactivation in the cerebellum not only occurs during motor tasks but also at rest. A functional MRI study showed increased spontaneous neuronal activity in the cerebellum in the resting state in patients with akinesia/rigidity PD (Wu et al. 2009).

On the other hand, a specific metabolic pattern was identified in patients with akinesia/rigidity PD using ${ }^{18} \mathrm{~F}$ fluorodeoxy-glucose PET. This was characterized by hypermetabolism in the striatum, thalamus, pons and cerebellum, together with hypometabolism in the supplementary motor cortex, premotor cortex and parieto-occipital association areas (Eidelberg 2009). In addition, it was found that patients with PD had significantly greater activation in the bilateral cerebellum, right thalamus and left midbrain/substantia nigra compared with the control subjects during motor exercise (Jahanshahi et al. 2010). It has been suggested that the cerebellar hyperactivity may serve to compensate the defective function in the basal ganglia (Sabatini et al. 2000; Wu and Hallett 2005). Other studies have viewed the hyperactivation in the cerebellum as a compensatory effort to maintain the decline in cognitive function in $\mathrm{PD}$ arising from the metabolic reduction in frontal and parietal association areas (Huang et al. 2007a, 2007b). The suggested compensatory role of the present increase in cerebellar activity depends on the studies showing the absence of PD motor symptoms in spite of the loss of $50 \%$ of the dopaminergic neurons in the substantia nigra and 65\% of dopamine level in the striatum (Lee et al. 2000). The lack of observed motor pathology despite significant cell loss indicates the existence of redundancy and/or compensatory mechanisms that serve to delay the onset of symptoms and preserve an optimal level of motor function (Bezard et al. 2001). Supporting this suggestion, the study of Heman et al. (2012) showed that the hyperactivation level in the cerebellar Purkinje cells correlated with the level of dopaminergic neuronal loss in the substantia nigra in Monkeys model of PD. Alternatively, it has been argued that hyperactivation could be related to specific signs of the disease such as rigidity (Kleine et al. 2001; Pierantozzi et al. 2001).

Whether the increase in the cerebellar activity is a part of the pathological condition of PD or serves to compensate the reduced motor cortical activity, the hyperactivation of the cerebellum in the Parkinsanian rat model could be mediated by the present increase in the cerebellar excitatory amino acid neurotransmitters; glutamate and aspartate together with the decrease in the inhibitory GABA, glycine and taurine neurotransmitters.

All glutamate is formed from glucose within the CNS because glutamate does not readily cross the blood-brain barrier (Gruetter et al. 1994). Therefore, the present increase in glutamate in the cerebellum of rat model could be explained by the reported increase in the rate of metabolism through tricarboxylic acid cycle.

Although the increase in the excitatory neurotransmitters may compensate for the deficits in the functions of the motor cortex, the present increase in glutamate and aspartate may have negative insults. Glutamate excitotoxicity together with oxidative stress may lead to neuronal death (Schulz et al. 2000; Sayre et al. 2001). Several studies have shown that the increase in the excitatory amino acid glutamate in the synapse results in excitotoxicity and can cause, in severe cases, neurodegeneration. The excessive stimulation of the amino acid receptor NMDA results in massive influx of calcium which is the main cause for neurodegeneration (Manev et al. 1989). The inhibitory amino acid neurotransmitters can counteract the increase in excitatory neurotransmitters and alleviate its hyperexcitability. However, the present recorded decrease in GABA, glycine and taurine may exaggerate the state of excitotoxicity. Dysfunction of GABAergic neurons such as the imbalanced generation of glutamatergic and GABAergic neurons is implicated as a cause of various neurodevelopmental disorders (Ben-Ari et al. 2007; Rossignol 2011).

Cerebellar Purkinje neurons release GABA, which exerts inhibitory actions on the dentate nucleus and certain deep cerebellar output neurons, thereby reducing the transmission of nerve impulses and enabling Purkinje cells to regulate and coordinate motor movements (Bowery et al. 2002).

The cerebellar nuclei have different types of projection neurons: output neurons as glutamatergic principal cells projecting to premotor structures or glycine-containing large neurons of the medial nucleus supplying brainstem nuclei (Wassef et al. 1986; Bagnall et al. 2009), small GABAergic neurons mediating the nucleo-olivary feedback loop (De Zeeuw et al. 1997), and nucleo-cortical neurons (Houck and Person 2014). A massive GABAergic input projects from the Purkinje cells found in the cerebellar cortex to all these neuronal types (De Zeeuw and Berrebi 1995; Uusisaari and Knöpfel 2008), thereby controlling the output of these nuclei (Person and Raman 2012; Chaumont et al. 2013). The glycine immunoreactivity of many small somata in the cerebellar nuclei (Bäurle and Grüsser-Cornehls 1997; Zeilhofer et al. 2005) and the abundance of glycinergic synapses in the cerebellar nuclei of wild-type animals (De Zeeuw and Berrebi 1995) and Purkinje cell degeneration (PCD) mutants (Bäurle and 
Grüsser-Cornehls 1997) established the inhibitory nature of these local neurons.

The present decrease in GABA and glycine levels results in a shift in the GABA/glutamate balance towards the excitatory state. This in turn may explain many of the tremors that have been observed with PD patients. Several studies reported that the decrease in GABAergic activity is the main cause of essential tremors (Paris-Robidas et al. 2012). Thus, the recorded decrease in GABA and glycine in the present study may reduce the control on the excitability mediated by glutamate and aspartate.

The present changes in amino acids were accompanied by a state of oxidative stress in the cerebellum under the effect of rotenone as clear from the significant increase in lipid peroxidation and $\mathrm{NO}$ and the significant decrease in GSH. In addition, a significant decrease in $\mathrm{AChE}$ and a significant increase in $\mathrm{Na}^{+}, \mathrm{K}^{+}$-ATPase activities were obtained in the PD rat model.

It has been reported that excessive NMDA activation by glutamate could lead to massive influx of calcium ions. Intracellular calcium overload has a crucial role in disrupting calcium homeostasis. This mechanism mediates the production of free radicals and initiation of oxidative stress. Therefore, the present recorded increase in free radical will attack the neuronal cell membrane causing the observed increase in lipid peroxidation. Exacerbating this effect is the vulnerability of brain tissue to oxidative stress due to the high consumption of oxygen, high level of polyunsaturated fatty acids, presence of redox-active transition metals such as $\mathrm{Cu}^{2+}$ and $\mathrm{Fe}^{2+}$ and deficiency of antioxidant enzymes (Halliwell 1992).

Moreover, calcium overload can stimulate nitric oxide synthase (Schulz et al. 1995). Thus, the significant increase in cerebellar NO level could be attributed to the activation of neuronal nitric oxide synthase. NO may interact with singlet oxygen (Korhonen et al. 2005) producing the potent damaging compound, peroxynitrite. Therefore the present increase in lipid peroxidation is a consequent result to the increased excitatory amino acid concentration beside elevated NO content induced by the intrastriatal injection of rotenone. In addition, the present decrease in cerebellar GSH may be due to its consumption in scavenging the generated free radicals.

The study of Tsakiris et al. (2000b) reported that AChE is very sensitive to free radicals that can inhibit the enzyme activity. This could interpret the present decrease in AChE activity. In the cerebellum, nicotinic acetylcholine receptors mediate the release of glutamate (Reno et al. 2004). Therefore, this decrease in AChE activity may also exaggerate the state of depolarization and excitation by elevating cerebellar ACh that can interact with nicotinic receptors.

Since $\mathrm{Na}^{+}, \mathrm{K}^{+}$-ATPase is the enzyme responsible for maintaining the membrane ionic gradient by the efflux of $\mathrm{Na}^{+}$and influx of $\mathrm{K}^{+}$, the present increase in the activity of cerebellar $\mathrm{Na}^{+}, \mathrm{K}^{+}$-ATPase enzyme could be viewed as a mechanism to counteract the resultant cerebellar excitation. Moreover, this increase in the enzyme activity could be a consequence of the hypermetabolism that has been reported in the cerebellum of Parkinsonian patients which results in an increase in the production of ATP, the main substrate for $\mathrm{Na}^{+}, \mathrm{K}^{+}$-ATPase.

There is strong evidence that inflammation in the brain, mediated by the activation of microglia, might be involved in the pathogenesis of PD (Mogi et al. 1994). It has been suggested that the microglia activated by rotenone may be responsible for the release of TNF- $\alpha$ which causes neuronal degeneration (Zaitone et al. 2012).

The present results showed a significant increase in TNF- $\alpha$ level indicating cerebellar inflammation. TNF- $\alpha$, a potent pro-inflammatory cytokine, has a promoting role in neuroinflammation-mediated progressive neurodegeneration (Montgomery and Bowers 2012). The increase in TNF- $\alpha$ level in the cerebellum of rat model of PD reflects the development of neuroinflammation as a consequence of the excitotoxicity and oxidative stress. It is clear that PD is a multifactorial disease which is characterized by selfperpetuating cascades involving a myriad of deleterious events at various stages including mitochondrial dysfunction, short-term and long-term oxidative and nitrosative stress, energy crisis, excitotoxicity, neuroinflammation and protein aggregation (Moore et al. 2005). These events work together to promote cell death.

The present histopathological examination of the cerebellum of rat model of PD induced by the intrastriatal injection of rotenone showed neurodegeneration in Purkinje cells as indicated from the marked necrosis of Purkinje cells, cytoplasmic shrinkage, pyknotic nuclei and chromatin condensation. These histopathological changes could be attributed to the excitotoxicity that arises from the excessive stimulation of NMDA by glutamate and aspartate which leads to $\mathrm{Ca}^{2+}$ overload, oxidative stress and neuroinflammation.

The present histopathological changes showing the degenerated Purkinje neurons may explain the decrease in the GABA levels in the cerebellum of PD rat model which could be attributed to the degeneration of the GABAergic Purkinje cells that control excitability by inhibiting glutamate release. This mechanism may underlie the resting tremors that occur in PD. The present results extend our understanding of the importance of the cerebellar excitatory and inhibitory amino acid neurotransmitters in the pathogenesis of PD. Accordingly, these changes should be taken into consideration during the treatment of PD. Restoring the balance between GABAergic and glutamatergic activity in the cerebellum may play a role in reducing resting tremors associated with PD.

Conflict of interest. All authors declare that they have no conflict of interest. 


\section{References}

Bäurle J., Grüsser-Cornehls U. (1997): Differential number of glycine- and GABA-immunopositive neurons and terminals in the deep cerebellar nuclei of normal and Purkinje cell degeneration mutant mice. J. Comp. Neurol. 382, 443-458

Bagnall M. W., Zingg B., Sakatos A., Moghadam S. H., Zeilhofer H. U., du Lac S. (2009): Glycinergic projection neurons of the cerebellum. J. Neurosci. 29, 10104-10110 https://doi.org/10.1523/JNEUROSCI.2087-09.2009

Bédard P., Sanes J. N. (2009): On a basal ganglia role in learning and rehearsing visual-motor associations. Neuroimage 47, $1701-1710$ https://doi.org/10.1016/j.neuroimage.2009.03.050

Ben-Ari Y., Gaiarsa J. L., Tyzio R., Khazipov R. (2007): GABA: a pioneer transmitter that excites immature neurons and generates primitive oscillations. Physiol. Rev. 87, 1215-1284 https://doi.org/10.1152/physrev.00017.2006

Bezard E., Crossman A. R., Gross C. E., Brotchie J. M. (2001): Structures outside the basal ganglia may compensate for dopamine loss in the presymptomatic stages of Parkinson's disease. FASEB J. 15, 1092-1094 https://doi.org/10.1096/fj.00-0637fje

Borghammer P., Østergaard K., Cumming P., Gjedde A., Rodell A., Hall N., Chakravarty M. M. (2010): A deformation-based morphometry study of patients with early-stage Parkinson's disease. Eur. J. Neurol. 17, 314-320 https://doi.org/10.1111/j.1468-1331.2009.02807.x

Bostan A. C., Dum R. P., Strick P. L. (2010): The basal ganglia communicate with the cerebellum. Proc. Nat. Acad. Sci. USA 107, 8452-8456 https://doi.org/10.1073/pnas.1000496107

Bowery N. G., Bettler B., Froestl W., Gallagher J. P., Marshall F., Raiteri M., Bonner T. I., Enna S. J. (2002): International union of pharmacology. XXXIII. Mammalian gamma-aminobutyric acid (B) receptors: Structure and function. Pharmacol. Rev. 54, 247-264 https://doi.org/10.1124/pr.54.2.247

Bowler K., Tirri R. (1974): The temperature characteristics of synaptic membrane ATPases from immature and adult rat brain. J. Neurochem. 23, 611-613 https://doi.org/10.1111/j.1471-4159.1974.tb06068.x

Chaumont J., Guyon N., Valera A. M., Dugue' G. P., Popa D., Marcaggi P., Gautheron V., Reibel-Foisset S., Dieudonne' S., Stephan A., et al. (2013): Clusters of cerebellar Purkinje cells control their afferent climbing fiber discharge. Proc. Natl. Acad. Sci. USA 110, 16223-16228 https://doi.org/10.1073/pnas.1302310110

De Zeeuw C. I., Berrebi A. S. (1995): Postsynaptic targets of Purkinje cell terminals in the cerebellar and vestibular nuclei of the rat. Eur. J. Neurosci. 7, 2322-2333 https://doi.org/10.1111/j.1460-9568.1995.tb00653.x

De Zeeuw C. I., Van Alphen A. M., Hawkins R. K., Ruigrok T. J. (1997): Climbing fibre collaterals contact neurons in the cerebellar nuclei that provide a GABAergic feedback to the inferior olive. Neuroscience 80, 981-986

Eidelberg D. (2009): Metabolic brain networks in neurodegenerative disorders: a functional imaging approach. Trends Neurosci. 32, 548-457 https://doi.org/10.1016/j.tins.2009.06.003

Ellman G. L. (1959): Tissue sulfhydryl groups. Arch. Biochem. Biophys. 82, 70-77

https://doi.org/10.1016/0003-9861(59)90090-6

Ellman G. L., Courtney K. D., Andres V., Feather-Stone R. M. (1961): A new and rapid colorimetric determination of acetylcholinesterase activity. Biochem. Pharmacol. 7, 88-95 https://doi.org/10.1016/0006-2952(61)90145-9

Gorun V., Proinov I., Baltescu V., Balaban G., Barzu O. (1978): Modified Ellman procedure for assay of cholinesterase in crudeenzymatic preparations. Anal. Biochem. 86, 324-326 https://doi.org/10.1016/0003-2697(78)90350-0

Gruetter R., Novotny E. J., Boulware S. D., Mason G. F., Rothman D. L., Shulman G. I., Prichard J. W., Shulman R. G. (1994): Localized 13C NMR spectroscopy in the human brain of amino acid labeling from D-[1-13C]glucose. J. Neurochem. 63,1377-1385 https://doi.org/10.1046/j.1471-4159.1994.63041377.x

Halliwell B. (1992): Reactive oxygen species and the central nervous system. J. Neurochem. 59, 1609-1623 https://doi.org/10.1111/j.1471-4159.1992.tb10990.x

Haslinger B., Erhard P., Kampfe N., Boecker H., Rummeny E., Schwaiger M., Conrad B., Ceballos-Baumann A. O. (2001): Event-related functional magnetic resonance imaging in Parkinson's disease before and after levodopa. Brain 124, 558-570 https://doi.org/10.1093/brain/124.3.558

Helmich R. C., Janssen M. J., Oyen W. J., Bloem B. R., Toni I. (2011): Pallidal dysfunction drives a cerebellothalamic circuit into Parkinson tremor. Ann. Neurol. 69, 269-281

https://doi.org/10.1002/ana.22361

Heman P., Barcia C., Gómez A., Ros C. M., Ros-Bernal F., Yuste J. E., de Pablos V., Fernandez-Villalba E., Toledo-Cárdenas M. R., Herrero M. T. (2012): Nigral degeneration correlates with persistent activation of cerebellar Purkinje cells in MPTP-treated monkeys. Histol. Histopathol. 27, 89-94

Hornykiewicz O. (2006): The discovery of dopamine deficiency in the parkinsonian brain. J. Neural. Transm. 70, 9-15 https://doi.org/10.1007/978-3-211-45295-0_3

Hoshi E., Tremblay L., Féger J., Carras P. L., Strick P. L. (2005): The cerebellum communicates with the basal ganglia. Nat. Neurosci. 8, 1491-1493 https://doi.org/10.1038/nn1544

Houck B. D., Person A. L. (2014): Cerebellar loops: a review of the nucleocortical pathway. Cerebellum 13, 378 -385 https://doi.org/10.1007/s12311-013-0543-2

Huang C., Mattis P., Tang C., Perrine K., Carbon M., Eidelberg D. (2007a): Metabolic brain networks associated with cognitive function in Parkinson's disease. Neuroimage 34, 714-723 https://doi.org/10.1016/j.neuroimage.2006.09.003

Huang C., Tang C., Feigin A., Lesser M., Ma Y., Pourfar M., Dhawan V., Eidelberg D. (2007b): Changes in network activity with the progression of Parkinson's disease. Brain 130, $1834-1846$ https://doi.org/10.1093/brain/awm086

Jahanshahi M., Jones C. R., Zijlmans J., Katzenschlager R., Lee L., Quinn N., Frith C. D., Lees A. J. (2010): Dopaminergic modulation of striato-frontal connectivity during motor timing in Parkinsons disease. Brain 133, 727-745 https://doi.org/10.1093/brain/awq012 
Jiao J., Nakajima A., Janssen W. G. M., Bindokas V. P., Xiong X., Morrison J. H., Brorson J. R., Tang Y. P. (2008): Expression of NR2B in cerebellar granule cells specifically facilitates effect of motor training on motor learning. PLoS One 3, 1684 https://doi.org/10.1371/journal.pone.0001684

Khadrawy Y. A., Mourad I. M., Mohammed H. S., Noor N. A., Ezz H. S. A. (2016): A study on the possible therapeutic role of Panax ginseng extract against a rat model of Parkinson's disease induced by intrastriatal rotenone injection. Int. J. Clin. Exp. Med. 9, 3831-3841

Kleine B. U., Praamstra P., Stegeman D. F., Zwarts M. J. (2001): Impaired motor cortical inhibition in Parkinson's disease: motor unit responses to transcranial magnetic stimulation. Exp. Brain Res. 138, 477-483 https://doi.org/10.1007/s002210100731

Korhonen R., Lahti A., Kankaanranta H., Moilanen E. (2005): Nitric oxide production and signaling in inflammation. Curr. Drug Targets Inflamm. Allergy 4, 471-479 https://doi.org/10.2174/1568010054526359

Lee C. S., Samii A., Sossi V., Ruth T. J., Schulzer M., Holden J. E., Wudel J., Pal P. K., de la Fuente-Fernandez R., Calne D. B., Stoessl A. J. (2000): In vivo positron emission tomographic evidence for compensatory changes in presynaptic dopaminergic nerve terminals in Parkinson's disease. Ann. Neurol. 47, 493-503 https://doi.org/10.1002/1531-8249(200004)47:4<493::AID-ANA13>3.0.CO;2-4

Lewis M. M., Du G., Sen S., Kawaguchi A., Truong Y., Lee S., Mailman R. B., Huang X. (2011): Differential involvement of striato- and cerebello-thalamo-cortical pathways in tremorand akinetic/rigid-predominant Parkinson's disease. Neuroscience $177,230-239$ https://doi.org/10.1016/j.neuroscience.2010.12.060

Manev H., Favaron M., Guidotti A., Costa E. (1989): Delayed increase of $\mathrm{Ca} 2+$ influx elicited by glutamate: role in neuronal death. Mol. Pharmacol. 36, 106-112

Márquez F. J., Quesada A. R., Sánchez-Jiménez F., Mú-ez De Castro I. (1986): Determination of 27 dansyl amino acid derivatives in biological fluids by reversed-phase high-performance liquid chromatography. J. Chromatogr. 380, 275-283 https://doi.org/10.1016/S0378-4347(00)83656-7

Mel B. W., Schiller J. (2004): On the fight between excitation and inhibition:location is everything. Sci. STKE: PE 44

Mogi M., Harada M., Riederer P., Narabayashi H., Fujita K., Nagatsu T. (1994): Tumor necrosis factor- $\alpha$ (TNF- $\alpha$ ) increases both in the brain and in the cerebrospinal fluid from parkinsonian patients. Neurosci. Lett. 165, 208-210 https://doi.org/10.1016/0304-3940(94)90746-3

Montgomery S. L., Bowers W. J. (2012): Tumor necrosis factoralpha and the roles it plays in homeostatic and degenerative processes within the central nervous system. J. Neuroimmune Pharmacol. 7, 42-59 https://doi.org/10.1007/s11481-011-9287-2

Moore D. J., West A. B., Dawson T. M. (2005): Molecular pathophysiology of Parkinson's disease. Ann. Rev. Neurosci. 28, 57-87 https://doi.org/10.1146/annurev.neuro.28.061604.135718

Moshage H., Kok B., Huizenga J. R. (1995): Nitrite and nitrate determination in plasma: a critical evaluation. Clin. Chem. 41, 892-896
Mulcahy P., Walsh S., Paucard A., Rea K., Dowd E. (2011): Characterisation of a novel model of Parkinson's disease by intrastriatal infusion of the pesticide rotenone. Neuroscience 181, 234-242 https://doi.org/10.1016/j.neuroscience.2011.01.038

Paris-Robidas S., Brochu E., Sintes M., Emond V., Bousquet M., Vandal M., Pilote M., Tremblay C., Di Paolo T., Rajput A. H., Rajput A., Calon F. (2012): Defective dentate nucleus GABA receptors in essential tremor. Brain 135, 105-116 https://doi.org/10.1093/brain/awr301

Person A. L., Raman I. M. (2012): Purkinje neuron synchrony elicits timelocked spiking in the cerebellar nuclei. Nature 481, 502-505 https://doi.org/10.1038/nature10732

Pierantozzi M., Palmieri M. G., Marciani M. G., Bernardi G., Giacomini P., Stanzione P. (2001): Effect of apomorphine on cortical inhibition in Parkinson's disease patients: a transcranial magnetic stimulation study. Exp. Brain Res. 141, 52-62 https://doi.org/10.1007/s002210100839

Reno L. A., Zago W., Markus R. P. (2004): Release of [3H]-Lglutamate by stimulation of nicotinic acetylcholine receptors in rat cerebellar slices. Neuroscience 124, 647-653 https://doi.org/10.1016/j.neuroscience.2003.12.023

Rolland A. S., Herrero M. T., Garcia-Martinez V., Ruberg M., Hirsch E. C., Francois C. (2007): Metabolic activity of cerebellar and basal ganglia-thalamic neurons is reduced in parkinsonism. Brain 130, 265-275 https://doi.org/10.1093/brain/awl337

Rossignol E. (2011): Genetics and function of neocortical GABAergic interneurons in neurodevelopmental disorders. Neural. Plast. 2011, 649325 https://doi.org/10.1155/2011/649325

Ruiz-Larrea M. B., Leal A. M., Liza M., Lacort M., de Groot H. (1994): Antioxidant effects of estradiol and 2-hydroxyestradiol on iron-induced lipid peroxidation of rat liver microsomes. Steroids 59, 383-388 https://doi.org/10.1016/0039-128X(94)90006-X

Sabatini U., Boulanouar K., Fabre N., Martin F., Carel C., Colonnese C., Bozzao L., Berry I., Montastruc J. L., Chollet F., Rascol O. (2000): Cortical motor reorganization in akinetic patients with Parkinson's disease: a functional MRI study. Brain 123, 394-403 https://doi.org/10.1093/brain/123.2.394

Sanacora G., Gueorguieva R., Epperson C. N., Wu Y. T., Appel M., Rothman D. L., Krystal J. H., Mason G. F. (2004): Subtypespecific alterations of gamma-aminobutyric acid and glutamate in patients with major depression. Arch. Gen. Psychiatry 61, 705-713 https://doi.org/10.1001/archpsyc.61.7.705

Saransaari P., Oja S. S. (1997): Enhanced GABA release in celldamaging conditions in the adult and developing mouse hippocampus. Int. J. Dev. Neurosci. 15, 163-174 https://doi.org/10.1016/S0736-5748(97)80001-9

Saransaari P., Oja S. S. (1998): Release of endogenous glutamate, aspartate, GABA, and taurine from hippocampal slices from adult and developing mice under cell-damaging conditions. Neurochem. Res. 23, 563-570 https://doi.org/10.1023/A:1022494921018 
Sayre L. M., Smith M. A., Perry G. (2001): Chemistry and biochemistry of oxidative stress in neurodegenerative disease. Curr. Med. Chem. 8, 721-738 https://doi.org/10.2174/0929867013372922

Schmidt W. J., Bubser M., Hauber W. (1992): Behavioural pharmacology of glutamate in the basal ganglia. J. Neural. Transm. Suppl. 38, 65-89

Schulz J. B., Matthews R. T., Beal M. F. (1995): Role of nitric oxide in neurodegenerative diseases. Curr. Opin. Neurol. 8, 480-486 https://doi.org/10.1097/00019052-199512000-00016

Schulz J. B., Lindenau J., Seyfried J., Dichgans J. (2000): Glutathione, oxidative stress and neurodegeneration. Eur. J. Biochem. 267, 4904-4911 https://doi.org/10.1046/j.1432-1327.2000.01595.x

Strick P. L., Dum R. P., Fiez J. A. (2009): Cerebellum and nonmotor function. Ann. Rev. Neurosci. 32, 413-434 https://doi.org/10.1146/annurev.neuro.31.060407.125606

Takada M., Sugimoto T., Hattori T. (1993): MPTP neurotoxicity to cerebellar purkinje cells in mice. Neurosci. Lett. 150, 49-52 https://doi.org/10.1016/0304-3940(93)90105-T

Tapuhi Y., Schmidt D. E., Linder W., Karger B. L. (1981): Dansylation of amino acids for high-performance liquid chromatography analysis. Anal. Biochem. 115, 123-129 https://doi.org/10.1016/0003-2697(81)90534-0

Tsakiris S., Angelogianni P., Schulpis K. H., Behrakis P. (2000a) Protective effect of 1-cysteine and glutathione on rat brain $\mathrm{Na}+, \mathrm{K}+$-ATPase inhibition induced by free radicals. Z. Naturforsch. 55, 271-277 https://doi.org/10.1515/znc-2000-3-421

Tsakiris S., Angelogianni P., Schulpis K. H., Stavridis C. (2000b): Protective effect of $\mathrm{L}$-phenylalanine on rat brain acetylcholinesterase inhibition induced by free radicals. Clin. Biochem. 33, 103-106 https://doi.org/10.1016/S0009-9120(99)00090-9

Uusisaari M., Knöpfel T. (2008): GABAergic synaptic communication in the GABAergic and non-GABAergic cells in the deep cerebellar nuclei. Neuroscience 156, 537-549 https://doi.org/10.1016/j.neuroscience.2008.07.060

Wassef M., Simons J., Tappaz M. L., Sotelo C. (1986): Non-Purkinje cell GABAergic innervation of the deep cerebellar nuclei a quantitative immunocytochemical study in C57BL and in Purkinje cell degeneration mutant mice. Brain Res. 399, $125-135$ https://doi.org/10.1016/0006-8993(86)90606-2

Watanabe D., Inokawa H., Hashimoto K., Suzuki N., Kano M., Shigemoto R., Hirano T., Toyama K., Kaneko S., Yokoi M. et al. (1998): Ablation of cerebellar Golgi cells disrupts synaptic integration involving GABA inhibition and NMDA receptor activation in motor coordination. Cell 95, 17-27 https://doi.org/10.1016/S0092-8674(00)81779-1

Wu T., Hallett M. (2005): A functional MRI study of automatic movements in patients with Parkinson's disease. Brain 128, 2250-2259 https://doi.org/10.1093/brain/awh569

Wu T., Wang L., Chen Y., Zhao C., Li K., Chan P. (2009):Changes of functional connectivity of the motor network in the resting state in Parkinson's disease. Neurosci. Lett. 460, 6-10 https://doi.org/10.1016/j.neulet.2009.05.046

Wu T., Wang L., Hallett M., Li K., Chan P. (2010): Neural correlates of bimanual anti-phase and in-phase movements in Parkinson's disease. Brain 133, 2394-2409 https://doi.org/10.1093/brain/awq151

Wu T., Hallett M. (2013): The cerebellum in Parkinson's disease. Brain 136, 696-709 https://doi.org/10.1093/brain/aws360

Zaitone S. A., Abo-Elmatty D. M., Elshazly S. M. (2012): Piracetam and vinpocetine ameliorate rotenone-induced Parkinsonism in rats. Indian J. Pharmacol. 44, 774-779 https://doi.org/10.4103/0253-7613.103300

Zeilhofer H. U., Studler B., Arabadzisz D., Schweizer C., Ahmadi S., Layh B., Bösl M. R., Fritschy J. M. (2005): Glycinergic neurons expressing enhanced green fluorescent protein in bacterial artificial chromosome transgenic mice. J. Comp. Neurol. 482, 123-141

https://doi.org/10.1002/cne.20349

Received: April 18, 2016

Final version accepted: July 11, 2016

First published online: November 30, 2016 